\title{
A CRITICAL STUDY OF HAMILTON-STEWART'S PRINCIPLE FOR THE ANALYSIS OF HEMODYNAMICS
}

\section{-A MATHEMATICAL ANALYSIS}

\author{
Toshiro Sato, M. D.* \\ Department of Physical Therapy and Medicine, Faculty of Medicine, \\ University of Tokyo \\ (Director: Prof. Yoshio Oshima, M. D.)
}

Blood runs with varying amounts of flow per unit of time through the heart and blood vessels different in width and length in the different organs.

The problem here is to study the dilution process of the substances which are supposed not to pass the walls of blood vessels, when they are injected at some point of this circulatory system in various wave forms of in-put. It might be most desirable that the theory of dilution process should be constructed on the basic law of physics, such as hydrodynamics of viscous fluid in the heart and vessels, and diffusion theory of the injected substances. It seems however that the study in this direction will be difficult at the present stage of progress of physics and of our knowledge about the physical features of the heart and blood vessels. For instance we do not know how the peripheral arteries, arteriols and capillaries are connected with each other or what are their elastic coefficient, and rheologic features of the blood are also far from being completely known. It is therefore hardly acceptable that the result of the experiment with a model of circulation could precisely predict any concentration curve of the injected dye in the circulatory system of the living body.

HAMilton et $\mathrm{al}^{1)}$ found in a one-way perfusion of the heart and lungs that decending limbs of the curve of dye concentration against time plotted as a straight line on a semilogarithmic paper. This finding has been considered as a proof of enabling a calculation of both flow and volume by extrapolating the initial exponential segment. They stated that the non-exponential curves obtained in perfusing only through the lungs, are changed into exponential when they are attached to the mixing chamber of anatomical size relations.

Received for Publication February 1, 1963.

* 佐藤登志郎

The outline of this study was reported at the general meeting of Japanese Society of Circulation (April '62) at the general conference of Japanese Physiological Society, (July '62), and at the IV. World Congress of Cardiology (in México, Oct. '62) 
$\mathrm{hT}$ is seems to indicate that the time constant of the mixing chamber ( $T$ of exponential dilution as $e^{-t / T}$ ) were large enough in their experiment to overshadow the nonexponential segment of response through the lungs, and that the perfusion might produce different (nonexponential) patterns of concentration curves, when the physiological relations of the lungs and mixing chamber are different.

At any rate the theory of exponentiality or any other alternatives should be proved quantitatively on the observed dilution curves of the intact living body, before it is guaranteed as exactly applicable for any cases of dilution test. And for that purpose, calculation of recirculation curve will be needed.

The following mathematical analysis will start with finding a function of fitting the concentration curve of the primary circulation of the dyed fluid through the pulmonary circulatory system, and then the calculations will be made for the curve of recirculated dyes under the hypothesis of linearity.*

Thus obtained theoretical curves of primary circulation given from the clinical cases, added by concentration curves of recirculation and re-recirculation will be compared with the observed values. It will be shown that the true response curve of the primary circulation of the dye can be obtained by minimizing thediffer ence between the observed concentration and theoretically calculated figures by the least square method.

An experimental presentation of the primary response curve and recirculation curve will also be reported in confirmation of the result of the mathematical analysis.

\section{MATHEMATICAL ANALYSIS}

In the following analysis, the equations are often expressed by their Laplace transforms and the concept of transferfunctions ${ }^{2)}$ are used. It will help us to manifest the relations, simply and yet vividly, on the condition that they could be expressed by linear differential equations ${ }^{3}$.

(I) The block-diagram representation of the diluting effect. (FIG. 1)

Suppose a substance is injected into the right auricle $(i(t))$ and the concentration of the substance is measured at the initial portion of the aorta $(c(t))$.

Then we obtain by Laplace transformation,

$$
G(s)=\frac{C(s)}{I(s)}=\frac{\int_{0}^{\infty} c(t) e^{-s t} d t}{\int_{0}^{\infty} i(t) e^{-s t} d t}
$$

where $G(s)$ is a transfer function of the circulatory system with respect to diluting effect of the injected substance.

\footnotetext{
* The author used the linearity in the meaning of possibility of superposition.
} 


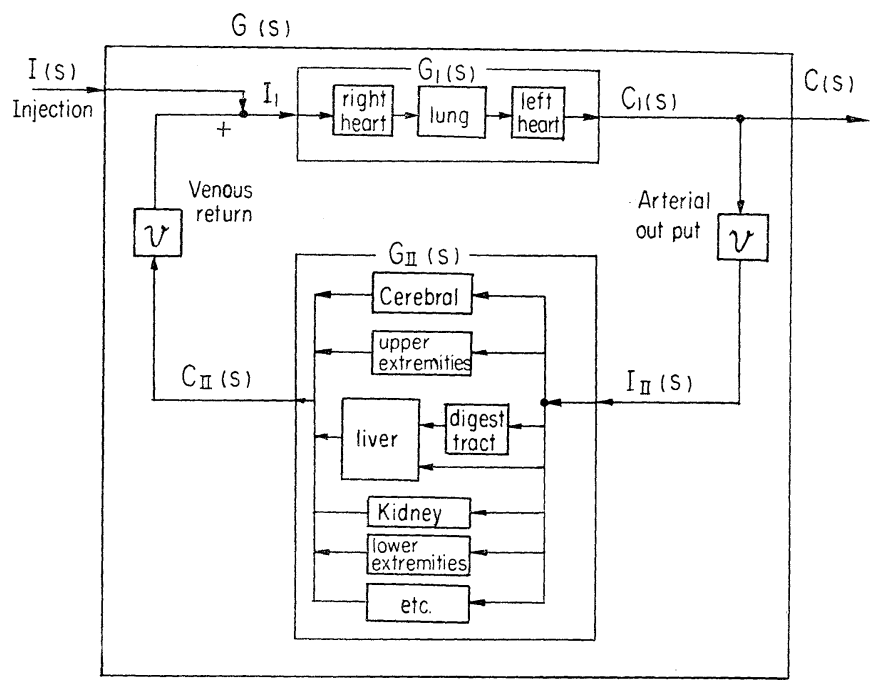

FIG. 1. Block diagram of calculation with the respect to the dilution curve of injected substances.

\begin{tabular}{|c|c|c|}
\hline $\begin{array}{l}\text { function of } \\
\text { time }\end{array}$ & $\begin{array}{l}\text { Laplace } \\
\text { transforms }\end{array}$ & Medical Significance of the function \\
\hline$c(t)$ & $C(s)$ & $\begin{array}{l}\text { the concentration of the dye in the } \\
\text { aorta, when the circulation is closed. }\end{array}$ \\
\hline$i(t)$ & $I(s)$ & $\begin{array}{l}\text { the rate which the dye is injected into } \\
\text { the right atrium. }\end{array}$ \\
\hline$c_{I}(t)$ & $C_{I}(s)$ & $\begin{array}{l}\text { the concentration of the dye in the } \\
\text { out-flow of the left ventricle. }\end{array}$ \\
\hline$i_{\mathrm{I}}(t)$ & $I_{\mathrm{I}}(s)$ & $\begin{array}{l}\text { the rate with which the dye enters } \\
\text { the right atrium. }\end{array}$ \\
\hline$c_{\mathrm{II}}(t)$ & $C_{\mathrm{II}}(s)$ & $\begin{array}{l}\text { the concentration of the dye at the } \\
\text { right atrium. }\end{array}$ \\
\hline \multirow[t]{4}{*}{$i_{\mathrm{II}}(t)$} & $I_{\mathrm{II}}(s)$ & $\begin{array}{l}\text { the rate with which the dye is } \\
\text { expelled out of the left ventricle. }\end{array}$ \\
\hline & $G_{1}(s)$ & $\begin{array}{l}\text { the transfer function of the } \\
\text { pulmonary circulatory system. }\end{array}$ \\
\hline & $G_{\perp I}(s)$ & $\begin{array}{l}\text { the transfer function of the systemic } \\
\text { circulatory system. }\end{array}$ \\
\hline & $G(s)$ & $\begin{array}{l}\text { the transfer function of the whole } \\
\text { circulatory system }\end{array}$ \\
\hline
\end{tabular}


Similarly, the transfer function of the pulmonary circulation can be defined by the next formula.

$$
G_{\mathrm{I}}(s)=\frac{C_{\mathrm{I}}(s)}{I_{\mathrm{I}}(s)}
$$

Concerning the dilution effect of the systemic circulation we have the $3 \mathrm{rd}$ equation as before,

$$
G_{\mathrm{II}}(s)=\frac{C_{\mathrm{II}}(s)}{I_{\mathrm{II}}(s)}
$$

where $G_{I I}(s)$ is considered to be a parallel and serial connection of the transfer functions of many elements of the systemic circulation.

(II) Mathematical developments.

The solution of the equations of dilution curves will be processed like that of electronic circuitry (see FIG. 1), as follows:

1) The response of the whole circulation. When the circulatory system is closed or in a physiological state, the change of the concentration of the substance which runs through the pulmonary system for the first time after the injection, will be given from the transfer function $G_{\mathrm{I}}(s)$. While in the secondtime circulation of the substance, the input at the right auricle $\left(I_{\mathrm{I}}(s)\right)$ will be a product of the heart out-put $v^{*}$ and the blood concentration of the substance at the right atrium.

This latter concentration may be regarded as the out-put $\left(C_{\mathrm{II}}(s)\right)$ in the systemic circulation, whose input is again $v$ multiplied by the response through the pulmonary circulatory system $\left(C_{\mathrm{I}}(s)\right)$ in its first time circulation. Thus in the whole series of response, the following equation is given:

$$
\begin{aligned}
G(s)= & G_{\mathrm{I}}(s)+G_{\mathrm{I}}\left(G_{\mathrm{II}} G_{\mathrm{I}} v^{2}\right)+G_{\mathrm{I}}\left(G_{\mathrm{II}} G_{\mathrm{I}} v^{2}\right)^{2} \\
& +G_{\mathrm{I}}\left(G_{\mathrm{II}} G_{\mathrm{I}} v^{2}\right)^{3}+\cdots \\
= & \frac{G_{\mathrm{I}}\left[1-\left(G_{\mathrm{I}} G_{\mathrm{II}} v^{2}\right)^{n}\right]}{1-\left(G_{\mathrm{I}} G_{\mathrm{II}} v^{2}\right)}
\end{aligned}
$$

The dilution curve of the substance, when the circulatory system is closed, is given from the equation (1), as

$$
C(s)=G(s) I(s)
$$

If the injection is completed in such a short time that the in-put might be considered as an impulse,

$$
i(t) \delta t=A,
$$

where A is a whole quantity of the injected substance.

By Laplace transformation,

\footnotetext{
* Here we must neglect the effect of pulsation and take the average value of heartoutput as $v$.
} 


$$
I(s)=\int_{0}^{\infty} i(t) e^{-s t} d t=\int_{0}^{\delta t} i(t) e^{-s t} d t=A
$$

Therefore,

$$
C(s)=A \cdot G(s)
$$

By the inverse Laplace transformation of the equation (4),

$$
c(t)=A\left\{f_{0}(t)+f_{1}(t)+f_{2}(t)+\cdots \cdots\right\}
$$

where

$$
f_{n}(t) \equiv \frac{1}{2 \pi i} \int_{t-i \infty}^{t+i \infty} G_{\mathrm{I}}(s)\left(G_{\mathrm{I}} G_{\mathrm{II}} v^{2}\right)^{n} e^{s t} d s
$$

corresponds to the $n$-th recirculation of the injected dyes.

When $n \rightarrow \infty$ and $t \rightarrow \infty$, or when a sufficient time has elapsed after the injection, it is self-evident that the diluting effect of the $n$-th recirculation of the substance becomes less and less, so that the geometrical series in the equation (4) converges, when infinite number of terms are taken

$$
\underset{n \rightarrow \infty}{G(s)}=\frac{G_{\mathrm{I}}\left[1-\left(G_{\mathrm{I}} G_{\mathrm{II}} v^{2}\right)^{n}\right]}{1-G_{\mathrm{I}} G_{\mathrm{II}} v^{2}}=\frac{G_{\mathrm{I}}}{1-G_{\mathrm{I}} G_{\mathrm{II}} v^{2}}
$$

We have to notice in this instance, that the above equation exists only when $t \rightarrow \infty$, for when $t$ is finite, the equation (4) and (9) ends up at a finite time.

The final concentration of the substance is thus given as

$$
\begin{gathered}
\lim c(t)=\lim S C(s)^{*} \\
=\lim _{s \rightarrow 0} \frac{I(s) G_{\mathrm{I}}(s) \cdot s}{I-G_{\mathrm{I}} G_{\mathrm{II}} v^{2}} \equiv A / N \equiv c_{\infty}
\end{gathered}
$$

in which $N$ may be defined as the circulating blood volume.

2) The response of the pulmonary circulation. The pool volume of the pulmonary circulation will be given by the following conceptional experiment.

Suppose a shunt is made between the initial portion of the aorta and the right auricle so that blood flowing out of the left ventricle might be given to the right heart without delay and with no change in the flow line. Suppose that this shunt has no volume. In this experiment, when the blood concentration of the injected substances (in amount of $A$ ) becomes $A / L$ after a sufficient elapse of time, then the circulating blood volume of the pulmonary system is $L$ by the definition. Such an experiment can not be performed actually, but the result is to be calculated, when $G_{I}(s)$ (of equation 2.) is known as in the following.

The entire transfer function is given in the Laplace transforms,

* This is a well-known formula for getting the stationary state of a transient response. 


$$
\begin{aligned}
G(s) & =G_{\mathrm{I}}(s)+G_{2}^{2} v+G_{1}^{3} v^{2}+\cdots \cdots \\
& =\frac{G_{\mathrm{I}}(s)\left(1-\left\{G_{\mathrm{I}}(s) v\right\}^{n}\right)}{1-G_{1}, v}
\end{aligned}
$$
(in $A$ ),

In the similar way as before (11), when the injection is given impulselike

$$
\underset{\substack{L \\ c_{L}(t) \\ n \rightarrow \infty}}{n \rightarrow \infty} \frac{A}{L}=\lim _{s \rightarrow 0} \frac{s G_{1}(s) \cdot A}{1-G_{1} v}
$$

from which $L$ is defined as the pool volume of the lungs and heart.

3) The response of the systemic circulation. The circulating blood volume $(M)$ may be given in quite a similar experiment, and will be calculated, using the transfer function, $G_{I I}(s)$,

Here evidently,

$$
\underset{\substack{M \\ c \rightarrow \infty \\ n \rightarrow \infty}}{c(t)} \equiv \frac{A}{M}=\lim _{s \rightarrow 3} \frac{s G_{\mathrm{II}}(s) A}{1-G_{\mathrm{II}} v}
$$

$$
N=M+L
$$

(III) The physiologically significant information which will be obtained from the dilution curve.

The transfer function in the pulmonary and systemic circulation calculated from the dilution curve of the injected dye should give informations concerning the hemodynamic features of the heart, lungs and various other organs. The followings are a few manifestations that are frequently discussed in the foregoing literatures.

1) The blood volumes of parts of the body are to be calculated as in the previous paragraph. (L, $M \& N)$

2) The out-put of the heart is led as follows.

When the recirculation is excluded, from the equation (2),

$$
\int_{0}^{\infty} i_{1}(t) d t=\int_{0}^{\infty} c_{1}(t) v(t) d t
$$

If the injected amount equals to $A$, the left side in the equation (16), will be just $A$.

Neglecting the effect of the pulsation and assuming $v(t)$ as constant $v$ during the observation we could lead the following equation.

$$
v=A / \int_{0}^{\infty} c_{1}(t) d t
$$

This is the well-known formula of calculating the cardiac out-put.

3) $N / v, L / v, M / v$. Let us call the above 3 ratios as "congestion indices" of the whole circulatory system, pulmonary circulatory system, and systemic circulatory system respectively. If the dilution curve is a simple exponential, the time constant of the function becomes the above index. 
(IV) The mathematical analysis of the clinical example of dilution curves appeared in the foregoing literatures.

In the clinical study, even the most detailed information that we can obtain about the dilution process is the concentration of the substance, in the aorta* after it is injected into the right heart through an inserted catheter. Here, the circulatory system should be closed without doubt. Our task is to find out an adequate method with which $G_{1} \& G_{\text {II }}$ can be separated from given $G$.

Since HAMILTON ${ }^{4}$, at the beginning of 20 -th century, it has been conventionally accepted that the dilution curve without recirculation falls down curving exponentially and the second up-folding of the curve means the effect of the recirculation.

Heart out-put, pulmonary blood volume, etc. have been calculated on this basis and even the automatic electronic device was invented for the faster and surer calculation of them, also on this basis. In view of these facts, the author proceeded the whole calculation of the dilution curves, assuming first of all the HAMilton's principle.

1) The data in the literaturas and some of ours reveal that the concentration curve before the so-called recirculation begins could be well fit by the following formula (18), where the injection is an impulse. (in $A$ )

$$
\begin{array}{r}
C_{1}(t)=K A\left[\frac{1}{\left(\frac{1}{T_{1}}-\frac{1}{T_{2}}\right)^{2}} e^{-\frac{t-t_{L}}{T_{2}}}-\left\{\frac{\left(t-t_{L}\right)}{\left(\frac{1}{T_{1}}-\frac{1}{T_{2}}\right)} e^{\left.\left.-\frac{t-t_{L}}{T_{2}}+\frac{1}{\left(\frac{1}{T_{1}} T_{2}\right)^{2}} e^{-\frac{t-t_{L}}{T_{1}}}\right\}\right]}\right.\right. \\
\text { (Where } \left.c_{1}(t)=0, \quad t<t_{L}\right)
\end{array}
$$

By the equation (2),

$$
G_{\mathrm{I}}(s)=K /\left(s+\frac{1}{T_{1}}\right)^{2}\left(s+\frac{1}{T_{2}}\right) \cdot e^{-s t} L
$$

$c_{1}(t)$ is the first term of the equation $c(t)$ (eq. 9). Here the author imagined in his mind that the $\frac{1}{\left(s+\frac{1}{T_{1}^{-}}\right)}$stood for the response of the left of right heart and the $\frac{1}{\left(s+\frac{1}{T_{2}}\right)}$ for that of the lungs, all of which are connected serially although the formula itself was led quite empiricallys). ' $f_{1}(t)$ ' in the equation (9) will be given as $L^{-1}\left[\frac{K}{\left(s+\frac{1}{T_{1}}\right)^{2}\left(s+\frac{1}{T_{2}^{-}}\right)}\right]^{2} v^{2} G_{2} e^{-2 s t} t_{L}$ which $G_{\mathrm{II}}(s)$ will apparently be more complicated than $G_{I}(s)$; but let us make $G_{I I}(s)$ as $H /\left(s+\frac{1}{T_{3}^{-}}\right) e^{-s t_{M} * *}$ for the time being.

* In case that the concentration of the dye at the right heart is simultaneously measured, STEPHENSON's precise method is readily applicable. This is also given by the simle calculation of $G_{I}$ from the equation ${ }^{2}$. 
Then,

$$
\begin{gathered}
f_{1}(t)=L^{-1} \frac{K^{2} H v^{2} e^{-s\left(t_{N}+t_{L}\right)}}{\left(s+\frac{1}{T_{1}}\right)^{4}\left(s+\frac{1}{T_{2}}\right)^{2}\left(s+\frac{1}{T_{3}}\right)}, \\
\text { where } t_{N}=t_{L}+t_{M}
\end{gathered}
$$

By the inverse Laplace transformation of the equation (20),

$$
\begin{aligned}
& C_{2}(t)=A f_{1}(t)=A H K^{2} v^{2}\left[e ^ { - \frac { t - t _ { L } - t _ { N } } { T _ { 3 } } } \frac { 1 } { ( \frac { 1 } { T _ { 1 } } - \frac { 1 } { T _ { 2 } } ) ^ { 2 } } \left\{\frac{4}{\left(\frac{1}{T_{1}}-\frac{1}{T_{2}}\right)^{3}\left(\frac{1}{T_{1}}-\frac{1}{T_{3}}\right)}\right.\right. \\
& +\frac{1}{\left(\frac{1}{T_{1}}-\frac{1}{T_{2}}\right)^{2}\left(\frac{1}{T_{2}}-\frac{1}{T_{3}}\right)^{2}}-\frac{4}{\left(\frac{1}{T_{1}}-\frac{1}{T_{2}}\right)^{3}\left(\frac{1}{T_{2}}-\frac{1}{T_{3}}\right)} \\
& \left.+\frac{3}{\left(\frac{1}{T_{1}}-\frac{1}{T_{2}}\right)^{2}\left(\frac{1}{T_{1}}-\frac{1}{T_{3}}\right)^{2}}+\frac{2}{\left(\frac{1}{T_{1}}-\frac{1}{T_{2}}\right)\left(\frac{1}{T_{1}}-\frac{1}{T_{3}}\right)^{3}}+\frac{1}{\left(\frac{1}{T_{1}}-\frac{1}{T_{3}}\right)^{4}}\right\} \\
& -e^{-\frac{t-t_{N}-t_{L}}{T_{2}}} \cdot \frac{1}{\left(\frac{1}{T_{1}}-\frac{1}{T_{2}}\right)^{4}\left(\frac{1}{T_{2}}-\frac{1}{T_{3}}\right)} \times\left\{\left(t-t_{N}-t_{L}\right)\right. \\
& \left.+\frac{1}{\left(\frac{1}{T_{2}}-\frac{1}{T_{3}}\right)}-\frac{4}{\left(\frac{1}{T_{1}}-\frac{1}{T_{2}}\right)}\right\}-e^{-\frac{t-t_{N}-t_{L}}{T_{2}}} \frac{1}{\left(\frac{1}{T_{1}}-\frac{1}{T_{3}}\right)\left(\frac{1}{T_{1}}-\frac{1}{T_{2}}\right)^{2}} \\
& \text {. }\left\{\frac{1}{6}\left(t-t_{N}-t_{L}\right)^{3}+\left(\frac{1}{2\left(\frac{1}{T_{1}}-\frac{1}{T_{3}}\right)}+\frac{1}{\left(\frac{1}{T_{1}}-\frac{1}{T_{2}}\right)}\right)\left(t-t_{N}-t_{L}\right)^{2}\right. \\
& +\left(\frac{1}{\left(\frac{1}{T_{1}}-\frac{1}{T_{3}}\right)^{2}}+\frac{2}{\left(\frac{1}{T_{1}}-\frac{1}{T_{3}}\right)\left(\frac{1}{T_{1}}-\frac{1}{T_{2}}\right)}+\frac{3}{\left(\frac{1}{T_{1}}-\frac{1}{T_{2}}\right)^{2}}\right)\left(t-t_{N}-t_{L}\right) \\
& +\frac{1}{\left(\frac{1}{T_{1}}-\frac{1}{T_{3}}\right)^{3}}+\frac{2}{\left(\frac{1}{T_{1}}-\frac{1}{T_{3}}\right)^{2}\left(\frac{1}{T_{1}}-\frac{1}{T_{2}}\right)} \\
& \left.+\left(\frac{3}{\left(\frac{1}{T_{1}}-\frac{1}{T_{3}}\right)\left(\frac{1}{T_{1}}-\frac{1}{T_{2}}\right)^{2}}+\frac{4}{\left(\frac{1}{T_{1}}-\frac{1}{T_{2}}\right)^{3}}\right\}\right]
\end{aligned}
$$

When the infinite time has elapsed, $c(t)$ will be $A / N$ as in the equation (11),

* $t_{L}$ : time interval between the injection of an indicator in the right auricle and its appearance in the aorta.

$t_{M}$ : time interval between the injection of the substances in the aorta its first appearance in the right auricle.

$K, H, T_{1}, T_{2}, T_{3}$ : unknown parameters to describe the dilution curves. $T_{i}$ may be explained as time constant of the diluting effect in a mixing chamber.

** The validity of this assumption will be discussed later on. 


$$
c_{\infty} \equiv A / N=\lim _{s \rightarrow \infty} \frac{I G_{\mathrm{I}} s}{1-G_{\mathrm{I}} G_{\mathrm{II} v^{2}}}=\lim _{s \rightarrow 3} \frac{A K s\left(s+\frac{1}{T_{3}}\right) e^{-s t_{L}}}{\left(s+\frac{1}{T_{1}}\right)^{2}\left(s+\frac{1}{T_{2}}\right)\left(s+\frac{1}{T_{3}}\right)-K H v^{2} e^{-s t_{N}}}
$$

As shown in the equation (17),

$$
\begin{gathered}
A=\int_{0}^{\infty} C_{1}(t) v d t=K A v \int_{0}^{\infty}\left\{\frac{1}{\left(\frac{1}{T_{1}}-\frac{1}{T_{2}}\right)} e^{-\frac{1}{T_{2}}}\right. \\
\left.-\left(\frac{t}{\left(\frac{1}{T_{1}}-\frac{1}{T_{2}}\right)}+\frac{1}{\left(\frac{1}{T_{1}}-\frac{1}{T_{2}}\right)^{2}}\right) e^{-\frac{1}{T_{1}}}\right\} d t=K A v T_{1}^{2} T_{2} \\
\therefore \quad K v=1 / T_{1}^{2} T_{2}
\end{gathered}
$$

Quite similarly,

$$
H v=1 / T_{3}
$$

Thus

$$
K H v^{2}=1 / T_{1}^{2} T_{2} T_{3}
$$

Then from the equations (21) \& (26),

$$
\begin{aligned}
A / N & =A K /\left(\frac{2}{T_{1} T_{2}}+\frac{1}{T_{1}^{2}}+\frac{T_{3}}{T_{1}^{2} T_{2}}+\frac{t_{N}}{T_{1}^{2} T_{2}}\right) \\
\therefore \quad T_{3} & =\left(N K-\frac{2}{T_{1} T_{2}}-\frac{1}{T_{1}^{2}}\right) T_{1}^{2} T_{2}-t_{N} \\
\text { or } \quad & =\left(A K / C \infty-\frac{2}{T_{1} T_{2}}-\frac{1}{T_{1}^{2}}\right) T_{1}^{2} T_{2}-t_{N}
\end{aligned}
$$

The calculation of the recirculation curve will therefore be carried out as follows: $T_{1}, T_{2}, K$ or $A K$ can be calculated in the equation (18) by solving the normal equations of least square method. Then from (28) $T_{3}$ is given, $H v, K v$ from (24), (25) \& (26). The recirculation is calculated from the equation (21), by using $T_{1}, T_{2}, T_{3}, A K, K v, H v$

2) Let us pick up some data in the literatures and consider the validity of the hypothesis of HAMILTON-STEWART's principle.

The TABLE 1 indicates the concentrations of $P^{32}$ labelled red corpuscles in blood, after it was injected into the vein and blood was taken out from an artery ${ }^{6}$.

The fitting of the concentration curve (till the bottom of the initial down slope) to the equation (18) was computed by using Deming's Least Square Method.

The computation of the recirculation curve was carried out with a digital computer (OKITAC), on an assumption that the minimum circulation time from an artery to a vein was already included in the $t_{L}$ of this observation. (or $\left.t_{N} \doteqdot t_{L}\right)$. If $t_{N}$ is longer than this value, as it is, $C_{2}(t)$ will be more delayed. 
TABLE 1

Blood concentration of $\mathrm{P}$-labeled red corpuscles in the artery after it was injected into the vein (NYLIN).

\begin{tabular}{|c|c|c|c|}
\hline $\begin{array}{l}\text { 1) (Case 5) } \\
\text { time (sec.) }\end{array}$ & $\begin{array}{l}\text { Normal } \\
\text { c. p. m. }\end{array}$ & $\begin{array}{l}\text { 2) (Case 1) } \\
\text { time (sec.) }\end{array}$ & $\begin{array}{l}\text { Heart Disease } \\
\text { c. p. m. }\end{array}$ \\
\hline 5 & - & \multirow[t]{15}{*}{30} & \multirow{15}{*}{-} \\
\hline 7 & - & & \\
\hline 9 & - & & \\
\hline 11 & - & & \\
\hline 13 & 56 & & \\
\hline 15 & 173 & & \\
\hline 17 & 226 & & \\
\hline 19 & 260 & & \\
\hline 21 & 250 & & \\
\hline 23 & 248 & & \\
\hline 25 & 189 & & \\
\hline 27 & 148 & & \\
\hline 29 & 109 & & \\
\hline 31 & 103 & & \\
\hline 33 & 52 & & \\
\hline 35 & 122 & 35 & 105 \\
\hline 37 & 119 & 40 & 348 \\
\hline 39 & 118 & 45 & 458 \\
\hline 41 & 122 & 50 & 435 \\
\hline 43 & 123 & 55 & 392 \\
\hline 45 & 113 & 60 & 360 \\
\hline 47 & 100 & 65 & 392 \\
\hline 49 & 103 & 70 & 283 \\
\hline 51. & 106 & 77 & 262 \\
\hline 53 & 99 & 85 & 243 \\
\hline 55 & 93 & 93 & 230 \\
\hline 57 & 95 & 100 & 238 \\
\hline 60 & 98 & 105 & 221 \\
\hline 120 & 104 & 110 & 220 \\
\hline 180 & 96 & 115 & 208 \\
\hline 240 & 107 & 120 & 218 \\
\hline 350 & 97 & 180 & 199 \\
\hline 600 & 86 & 300 & 204 \\
\hline \multirow[t]{4}{*}{900} & 88 & 420 & 169 \\
\hline & & 600 & 178 \\
\hline & & 900 & 178 \\
\hline & & 1800 & 173 \\
\hline
\end{tabular}


TABLE 2.

Calculated parameters of concentration (HAMILTON-STEWART's principle) and comparison of the calculated concentration with the observed values. (case 5 normal) $t_{N}=t_{L}$ of this observation $\left(12 \mathrm{sec}\right.$.), $t_{j}=33 \mathrm{sec}$. $T_{1} \ldots 3.07 \mathrm{sec} . T_{2} \cdots 5.12 \mathrm{sec} . A K \ldots 78.2$

\begin{tabular}{|c|c|c|c|c|}
\hline time & obs. val. & $C_{1}(t)$ & $C_{2}(t)$ & Cresid. \\
\hline 13 sec. & 56 & 29.5 & - & - \\
\hline 15 & 173 & 151.6 & - & - \\
\hline 17 & 226 & 244.3 & - & - \\
\hline 19 & 260 & 272.1 & - & - \\
\hline 21 & 250 & 259.9 & - & - \\
\hline 23 & 248 & 225.3 & - & - \\
\hline 25 & 199 & 183.3 & 0.0 & - \\
\hline 27 & 148 & 142.9 & 0.0 & - \\
\hline 29 & 109 & 107.9 & 0.0 & - \\
\hline 31 & 103 & 79.54 & 0.0 & - \\
\hline 33 & 52 & 57.6 & 0.0 & - \\
\hline 35 & 122 & 41.2 & 0.0 & 80.8 \\
\hline 37 & 119 & 29.1 & 5.6 & 74.3 \\
\hline 39 & 118 & 20.4 & 14.2 & 83.4 \\
\hline 41 & 122 & 14.2 & 24.5 & 83.3 \\
\hline 43 & 123 & 9.8 & 35.5 & 77.7 \\
\hline 45 & 113 & 6.7 & 46.1 & 60.2 \\
\hline 47 & 100 & 4.6 & 54.3 & 41.1 \\
\hline 49 & 105 & 3.2 & 63.3 & 36.5 \\
\hline 51 & 106 & 2.2 & 69.4 & 34.4 \\
\hline 53 & 99 & 1.5 & 73.6 & 23.9 \\
\hline 55 & 95 & 1.0 & 75.1 & 16.9 \\
\hline 57 & 96 & 0.7 & 75.9 & 18.4 \\
\hline 59 & - & 0.5 & 76.7 & 20.8 \\
\hline 61 & - & 0.3 & 75.5 & 22.2 \\
\hline 63 & - & 0.2 & 73.5 & 24.3 \\
\hline 65 & - & 0.1 & 70.9 & 27.0 \\
\hline 67 & - & 0.0 & 67.9 & 30.1 \\
\hline 69 & - & & 64.6 & 33.4 \\
\hline 71 & - & & 61.2 & 36.8 \\
\hline 73 & - & & 57.8 & 30.2 \\
\hline 75 & - & & 54.5 & 43.5 \\
\hline 77 & - & & 51.2 & 46.5 \\
\hline 79 & 96 & & 47.9 & 50.0 \\
\hline 81 & - & & 44.9 & 53.1 \\
\hline 83 & - & & 42.0 & 56.0 \\
\hline 85 & - & & 39.2 & 58.8 \\
\hline
\end{tabular}


TABLE 3.

Calculated parameters of concentration (by HAMILTON-STEWART's principle) and comparison of the calculated concentration with the observed values. (Case 1 heart disease)



\begin{tabular}{|c|c|c|c|c|}
\hline time & obs. val. & $C_{1}(t)$ & $C_{2}(t)$ & Cresid. \\
\hline 35 sec. & 105 & 158.2 & - & - \\
\hline 40 & 348 & 336.0 & - & - \\
\hline 45 & 458 & 419.9 & - & - \\
\hline 50 & 435 & 433.7 & - & - \\
\hline 55 & 392 & 411.0 & - & - \\
\hline 60 & 360 & 373.6 & - & - \\
\hline 65 & 392 & 232.4 & - & - \\
\hline 70 & 283 & 292.8 & - & - \\
\hline 77 & 262 & 240.4 & 0.07 & 21.7 \\
\hline 85 & 243 & 195.6 & 1.4 & 45.9 \\
\hline 93 & 230 & 159.7 & 8.0 & 62.3 \\
\hline 100 & 238 & 129.7 & 19.7 & 88.6 \\
\hline 105 & 221 & 113.1 & 31.1 & 76.8 \\
\hline 110 & 220 & 98.6 & 44.3 & 77.1 \\
\hline 115 & 208 & 85.4 & 58.3 & 64.3 \\
\hline 120 & 218 & 72.5 & 72.5 & 70.6 \\
\hline 130 & 200 & 64.0 & 99.0 & 37.0 \\
\hline 140 & 200 & 56.0 & 120.8 & 23.0 \\
\hline 150 & 200 & 48.0 & 136.4 & 15.6 \\
\hline 160 & 200 & 42.0 & 145.6 & 12.4 \\
\hline 170 & 200 & 36.0 & 149.3 & 14.7 \\
\hline 180 & 199 & 32.0 & 148.3 & 19.0 \\
\hline
\end{tabular}

The result is described in the TABLE 2, TABLE 3 and FIG. 2. They show that there are certain areas $(C$. resid.) which are not to be explained by the calculated concentration curves. And it is to be noted in these results, that the peak of recirculation was about 20 seconds later than that of the second curve that had been considered to indicate the peak of recirculation.

3). The explanation of the above discrepancy will be most easily and plausibly rendered by abandoning the hypothesis of simply exponentially descending slope and by adding some of the so-called recirculation to the primary response of the pulmonary circulation.

The author computed this additional response, assuming effectively that 


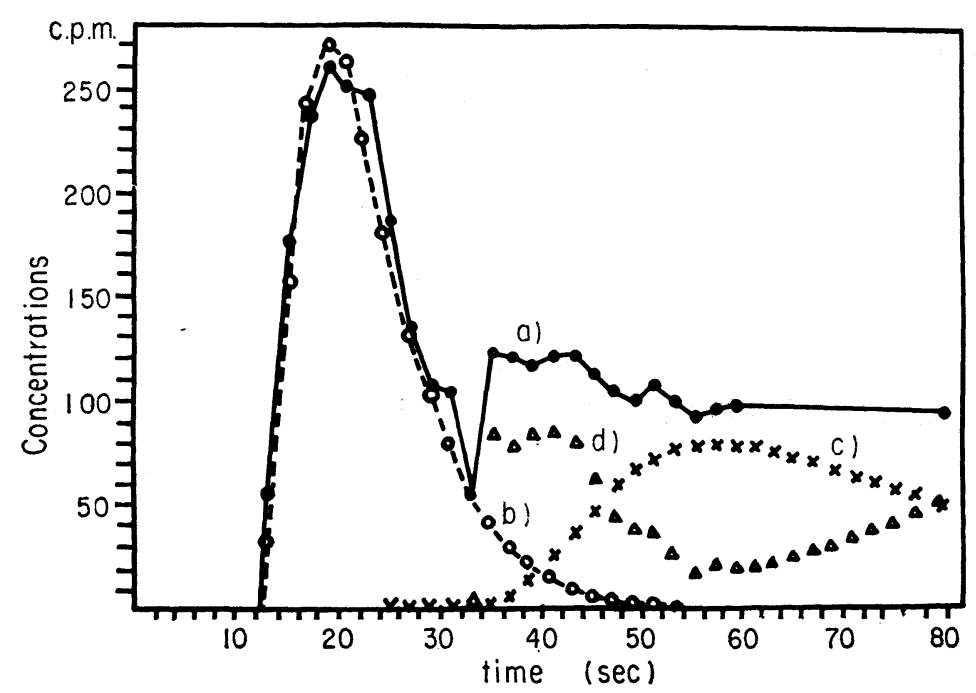

FIG. 2. The comparison of the calculated concentrations (by the Stewart's principle) with the observed values. (1 Case 5 Normal).
a) observed curves
b) $O C_{1}(t)$
c) $\times C_{2}(t)$
e) $\triangle$ Residues (Cresid.)

this also followed a similar curve as in the equation (18).

$$
\begin{aligned}
& C_{11}(t)=K A\left\{\frac{1}{\left(\frac{1}{T_{1}}-\frac{1}{T_{2}}\right)^{2}} e^{-\frac{t-t_{L}}{T_{3}}}-\left(\frac{t-t_{L}}{\left(\frac{1}{T_{1}}-\frac{1}{T_{2}}\right)}-\frac{1}{\left(\frac{1}{T_{1}}-\frac{1}{T_{2}}\right)^{2}}\right) e^{-\frac{t-t_{L}}{T_{1}}}\right\} \\
& C_{12}(t)=J A\left\{\frac{1}{\left(\frac{1}{T_{5}}-\frac{1}{T_{4}}\right)^{2}} e^{-\frac{t-t_{j}}{T_{2}}}-\left(\frac{t-t_{j}}{\left(\frac{1}{T_{5}}-\frac{1}{T_{4}}\right)}+\frac{1}{\left(\frac{1}{T_{5}}-\frac{1}{T_{4}}\right)^{2}}\right) e^{-\frac{t-t_{j}}{T_{2}}}\right\} \\
& \cdots \cdots \cdots \\
& \cdots \cdots \cdots
\end{aligned}
$$

$C_{12}(t)$ will be obtained by fitting the above equation (34) to the $C$.-residue (from $t_{j}$ ) using the least square method, as above, where the residual concentration is, Cresid. $(t)=$ Cob. $-\left(C_{11}(t)+C_{2}(t)\right)$

When we thus get $T_{4}, T_{5}$ and $J A$, define $\theta$ by

$$
\begin{gathered}
\int_{0}^{\infty} v C_{11}(t) d t=\theta A, \int_{0}^{\infty} v C_{12}(t) d t=(1-\theta) A \\
\text { where } 1>\theta>0
\end{gathered}
$$

${ }^{*} t_{j}$ : time interval between injection of the indicator in the right auricle and the first appearance of the additional curve.

$J, T_{4}, T_{5}$ : unknown parameters to describe the additional dilution curve. 
Therefore $\theta$ is calculated as

$$
\theta=\frac{K T_{2} T_{1}^{2}}{K T_{2} T_{1}^{2}+J T_{4} T_{5}^{2}}
$$

From this, $T_{3}$ is calculated as in the equation (29).

$$
\begin{aligned}
T_{3}= & \left(A K T_{2} T_{1}^{2}+A J T_{4} T_{5}^{2}\right) / C_{\infty}-2\left(\theta T_{1}+T_{5}(1-\theta)\right) \\
& -\left(T_{2} \theta+T_{5}(1-\theta)\right)-t_{L} \theta-(1-\theta) \cdot t_{j}-t_{M}
\end{aligned}
$$

From above all this, the recirculation curve can be computed from the next equation.

$$
C_{2}(t)=A f_{1}(t)=A H K^{2} v^{2}\left[e ^ { - \frac { t - t _ { L } - t _ { N } } { T _ { 3 } } } \frac { 1 } { ( \frac { 1 } { T _ { 1 } } - \frac { 1 } { T _ { 2 } } ) ^ { 2 } } \left\{\frac{4}{\left(\frac{1}{T_{1}}-\frac{1}{T_{2}}\right)^{3}\left(\frac{1}{T_{1}}-\frac{1}{T_{3}}\right)}\right.\right.
$$

beginning at $t=t_{L}+t_{N}$

$$
\begin{aligned}
& -\frac{4}{\left(\frac{1}{T_{1}}-\frac{1}{T_{2}}\right)^{3}\left(\frac{1}{T_{2}}-\frac{1}{T_{3}}\right)}+\frac{1}{\left(\frac{1}{T_{1}}-\frac{1}{T_{2}}\right)^{2}\left(\frac{1}{T_{2}}-\frac{1}{T_{3}}\right)^{2}} \\
& +\frac{3}{\left(\frac{1}{T_{1}}-\frac{1}{T_{2}}\right)^{2}\left(\frac{1}{T_{1}}-\frac{1}{T_{3}}\right)^{2}}+\frac{2}{\left(\frac{1}{T_{1}}-\frac{1}{T_{2}}\right)\left(\frac{1}{T_{1}}-\frac{1}{T_{3}}\right)^{3}} \\
& \left.+\frac{1}{\left(\frac{1}{T_{1}}-\frac{1}{T_{3}}\right)^{4}}\right\}-e^{-\frac{t-t_{L}-t_{N}}{T_{3}}} \cdot \frac{1}{\left(\frac{1}{T_{1}}-\frac{1}{T_{2}}\right)^{4}\left(\frac{1}{T_{2}}-\frac{1}{T_{3}}\right)} \\
& \times\left\{\left(t-t_{N}-t_{L}\right)+\frac{1}{\left(\frac{1}{T_{2}}-\frac{1}{T_{3}}\right)}-\frac{4}{\left(\frac{1}{T_{1}}-\frac{1}{T_{2}}\right)}\right\}-e^{-\frac{t-t_{N}-t_{L}}{T_{2}}} \\
& \frac{1}{\left(\frac{1}{T_{1}}-\frac{1}{T_{3}}\right)\left(\frac{1}{T_{1}}-\frac{1}{T_{2}}\right)^{2}} \times\left\{\frac{1}{6}\left(t-t_{N}-t_{L}\right)^{3}\right. \\
& +\left(\frac{1}{2\left(\frac{1}{T_{1}}-\frac{1}{T_{3}}\right)}+\frac{1}{\left(\frac{1}{T_{1}}-\frac{1}{T_{2}}\right)}\right)\left(t-t_{N}-t_{L}\right)^{2}+\left(\frac{1}{\left(\frac{1}{T_{1}}-\frac{1}{T_{3}}\right)^{2}}\right. \\
& \left.+\frac{2}{\left(\frac{1}{T_{1}}-\frac{1}{T_{3}}\right)\left(\frac{1}{T_{1}}-\frac{1}{T_{2}}\right)}+\frac{3}{\left(\frac{1}{T_{1}}-\frac{1}{T_{2}}\right)^{2}}\right)\left(t-t_{N}-t_{L}\right)+\frac{1}{\left(\frac{1}{T_{1}}-\frac{1}{T_{3}}\right)^{3}} \\
& \left.\left.+\frac{2}{\left(\frac{1}{T_{1}}-\frac{1}{T_{3}}\right)^{2}\left(\frac{1}{T_{1}}-\frac{1}{T_{2}}\right)}+\frac{3}{\left(\frac{1}{T_{1}}-\frac{1}{T_{3}}\right)\left(\frac{1}{T_{1}}-\frac{1}{T_{2}}\right)^{2}}+\frac{4}{\left(\frac{1}{T_{1}}-\frac{1}{T_{2}}\right)^{3}}\right\}\right] \\
& +A H J^{2} v^{2}\left[e^{-\frac{t-t_{M}-2 t_{j}}{T_{3}}} \times \frac{1}{\left(\frac{1}{T_{5}}-\frac{1}{T_{4}}\right)^{2}}\left\{\frac{4}{\left(\frac{1}{T_{5}}-\frac{1}{T_{4}}\right)^{3}\left(\frac{1}{T_{5}}-\frac{1}{T_{3}}\right)}\right.\right.
\end{aligned}
$$

beginning at $t=t_{M}+2 t_{j}$ 


$$
\begin{aligned}
& -\frac{4}{\left(\frac{1}{T_{5}}-\frac{1}{T_{4}}\right)^{3}\left(\frac{1}{T_{4}}-\frac{1}{T_{3}}\right)}-\frac{1}{\left(\frac{1}{T_{5}}-\frac{1}{T_{3}}\right)\left(\frac{1}{T_{4}}-\frac{1}{T_{3}^{-}}\right)^{2}} \\
& \left.+\frac{3}{\left(\frac{1}{T_{5}}-\frac{1}{T_{4}}\right)^{2}\left(\frac{1}{T_{5}}-\frac{1}{T_{3}}\right)^{2}}+\frac{2}{\left(\frac{1}{T_{5}}-\frac{1}{T_{4}}\right)\left(\frac{1}{T_{5}}-\frac{1}{T_{3}}\right)^{3}}+\frac{1}{\left(\frac{1}{T_{5}}-\frac{1}{T_{3}}\right)^{4}}\right\} \\
& -e^{-\frac{t-t_{M}-3 t_{j}}{T_{4}}} \cdot \frac{1}{\left(\frac{1}{T_{5}}-\frac{1}{T_{4}}\right)^{4}\left(\frac{1}{T_{2}}-\frac{1}{T_{3}}\right)} \cdot\left\{\left(t-t_{M}-2 t_{j}\right)\right. \\
& \left.+\frac{1}{\left(\frac{1}{T_{4}}-\frac{1}{T_{3}}\right)}-\frac{4}{\left(\frac{1}{T_{5}}-\frac{1}{T_{4}}\right)}\right\}-e^{-\frac{t-t_{M_{3}^{-2}}}{T_{5}}} \times \frac{1}{\left(\frac{1}{T_{5}}-\frac{1}{T_{3}}\right)\left(\frac{1}{T_{5}}-\frac{1}{T_{4}}\right)^{2}} \\
& \cdot\left\{\frac{1}{6}\left(t-t_{M}-2 t_{j}\right)^{3}+\left(\frac{1}{2\left(\frac{1}{T_{5}}-\frac{1}{T_{3}}\right)}+\frac{1}{\left(\frac{1}{T_{5}}-\frac{1}{T_{4}}\right)}\right)\left(t-t_{M}-2 t_{j}\right)^{2}\right. \\
& +\left(\frac{1}{\left(\frac{1}{T_{5}}-\frac{1}{T_{3}}\right)^{2}}+\frac{2}{\left(\frac{1}{T_{5}}-\frac{1}{T_{3}}\right)\left(\frac{1}{T_{5}}-\frac{1}{T_{4}}\right)}+\frac{3}{\left(\frac{1}{T_{5}}-\frac{1}{T_{4}}\right)^{2}}\right) \\
& \cdot\left(t-t_{M}-2 t_{j}\right)+\frac{1}{\left(\frac{1}{T_{5}}-\frac{1}{T_{3}}\right)^{3}}+\frac{2}{\left(\frac{1}{T_{5}}-\frac{1}{T_{3}}\right)^{2}\left(\frac{1}{T_{5}}-\frac{1}{T_{4}}\right)} \\
& \left.\left.+\frac{3}{\left(\frac{1}{T_{5}}-\frac{1}{T_{3}}\right)\left(\frac{1}{T_{5}}-\frac{1}{T_{4}}\right)^{2}}+\frac{4}{\left(\frac{1}{T_{5}}-\frac{1}{T_{4}}\right)^{3}}\right]\right]
\end{aligned}
$$

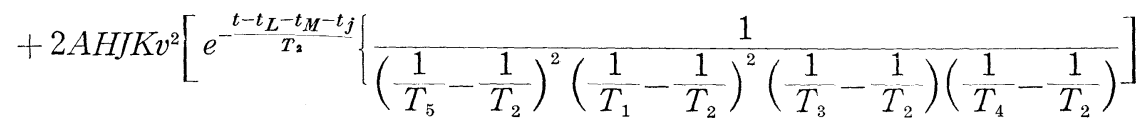

beginning at $t=t_{L}+t_{M}+t_{j}$

$$
\begin{aligned}
& +e^{-\frac{t-t_{L}-L_{M^{-}} t_{j}}{T_{3}}} \cdot\left\{\frac{1}{\left(\frac{1}{T_{5}}-\frac{1}{T_{3}}\right)^{2}\left(\frac{1}{T_{1}}-\frac{1}{T_{3}}\right)^{2}\left(\frac{1}{T_{2}}-\frac{1}{T_{3}}\right)\left(\frac{1}{T_{4}}-\frac{1}{T_{3}}\right)}\right\} \\
& +e^{-\frac{t-t_{L^{-}} L_{M^{-}} T_{j}}{T_{4}}} \cdot\left\{\frac{1}{\left(\frac{1}{T_{5}}-\frac{1}{T_{4}}\right)^{2}\left(\frac{1}{T_{1}}-\frac{1}{T_{4}}\right)^{2}\left(\frac{1}{T_{2}}-\frac{1}{T_{4}}\right)\left(\frac{1}{T_{3}}-\frac{1}{T_{4}}\right)}\right\} \\
& -e^{-\frac{t-t_{L}-t_{M}{ }^{-t_{j}}}{T_{1}}} \cdot \frac{1}{\left(\frac{1}{T_{1}}-\frac{1}{T_{2}}\right)\left(\frac{1}{T_{1}}-\frac{1}{T_{3}}\right)\left(\frac{1}{T_{1}}-\frac{1}{T_{4}}\right)\left(\frac{1}{T_{4}}-\frac{1}{T_{5}}\right)^{2}} \\
& \times\left\{t+\frac{1}{\left(\frac{1}{T_{1}}-\frac{1}{T_{2}}\right)}+\frac{1}{\left(\frac{1}{T_{1}}-\frac{1}{T_{3}}\right)}+\frac{1}{\left(\frac{1}{T_{1}}-\frac{1}{T_{4}}\right)}+\frac{1}{\left(\frac{1}{T_{5}}-\frac{1}{T_{1}}\right)}\right\} \\
& -e^{-\frac{t-t_{L}-t_{M}-t_{j}}{T^{\prime}}} \cdot \frac{1}{\left(\frac{1}{T_{5}}-\frac{1}{T_{2}}\right)\left(\frac{1}{T_{5}}-\frac{1}{T_{3}}\right)\left(\frac{1}{T_{5}}-\frac{1}{T_{4}}\right)\left(\frac{1}{T_{1}}-\frac{1}{T_{5}}\right)^{2}}
\end{aligned}
$$




$$
\left.\times\left\{t+\frac{1}{\left(\frac{1}{T_{5}}-\frac{1}{T_{2}}\right)}+\frac{1}{\left(\frac{1}{T_{5}}-\frac{1}{T_{3}}\right)}+\frac{1}{\left(\frac{1}{T_{5}}-\frac{1}{T_{4}}\right)}-\frac{2}{\left(\frac{1}{T_{5}}-\frac{1}{T_{1}}\right)}\right\}\right]
$$

This formula was calculated as the inverse Laplace transform of

$$
C_{2}(s)=A v^{2}\left\{\frac{K e^{-s t_{L}}}{\left(s+\frac{1}{T_{1}^{-}}\right)^{2}\left(s+\frac{1}{T_{2}^{-}}\right)}+\frac{J e^{-s t_{j}}}{\left(s+\frac{1}{T_{1}^{-}}\right)^{2}\left(s+\frac{1}{T_{4}^{-}}\right)}\right\}^{2} \cdot \frac{H}{\left(s+\frac{1}{T_{3}}\right)} \cdot e^{-s t_{M}}
$$

We iterate the same procedure from the equations (35) to (39), until a $C_{12}(t)$ becomes practically equal to $C$.-residue (calculated from this $C_{12}(t)$ and $C_{11}(t)$ ).

From the above mentioned curve, out-put $(v)$ and pool volume $(L)$ of the pulmonary circulation are to be calculated as follows.

$$
\begin{gathered}
v=\frac{1}{\left(K T_{1}^{2} T_{2}+J T_{4} T_{5}^{2}\right)} \\
L=v\left\{\theta\left(2 T_{1}+T_{2}+t_{L}\right)+(1-\theta)\left(2 T_{5}+T_{4}+t_{j}\right)\right\}
\end{gathered}
$$

The congestion index of the lesser circulation defined elsewhere will be

$$
\theta\left(2 T_{1}+T_{2}+t_{L}\right)+(1-\theta)\left(2 T_{5}+T_{4}+t_{j}\right)
$$

In the FIG. 3 and FIG. 4 with TABLE 4 are shown the results of the calculation on the data concerning a normal person and a patient with the heart

\begin{tabular}{|c|c|c|c|}
\hline 1 (case 5 ) & normal & 2 (case 1$)$ & heart disease \\
\hline$T_{1} \ldots$ & 3.07 & $T_{1} \ldots$ & $\ldots 5.1$ \\
\hline$T_{2} \ldots$ & 5.12 & $T_{2} \ldots$ & $\ldots 36.3$ \\
\hline$T_{4} \ldots$ & 10.0 & $T_{4} \ldots$ & $\ldots 20.0$ \\
\hline$T_{5} \ldots$ & 2.0 & $T_{5} \ldots$ & $\ldots 10.0$ \\
\hline$T_{3} \ldots$ & 28.05 & $T_{3} \ldots$ & . 50.05 \\
\hline$A K \ldots$ & 78.2 & $A K \ldots$ & $\ldots 24.8$ \\
\hline$A J \ldots$ & 37.8 & $A J \ldots$ & 2.0 \\
\hline$\theta$ & 0.72 & $\theta \ldots$ & 0.85 \\
\hline
\end{tabular}
disease respectively. It is clear from the above two data that in the normal person the primary response is composed of two curves, while in the patient

TABLE 4.

The parameters of $C_{11}(t)$ and $C_{12}(t)$ by the modified formulae in both cases.

The calculation was made on an assumption that the minimum circulation time from an artery to a vein was already included in the $t_{L}$ of this observation (or $t_{N} \fallingdotseq t_{L}$ ). If $t_{N}$ is longer than this value, $C_{2}(t)$ will be more delayed and $\theta$ will be smaller. 




FIG. 3. The calculated concentrations (by the new principle) and the observed values. (1 Case 5 Heart Disease)
a) observed curves
b) $\bigcirc C_{11}(t)$
c) $-\cdot-C_{12}(t)$
d) $\times C_{2}(t)$
e) $\triangle$ obs. val. $-\left(C_{11}(t)+C_{2}(t)\right)$

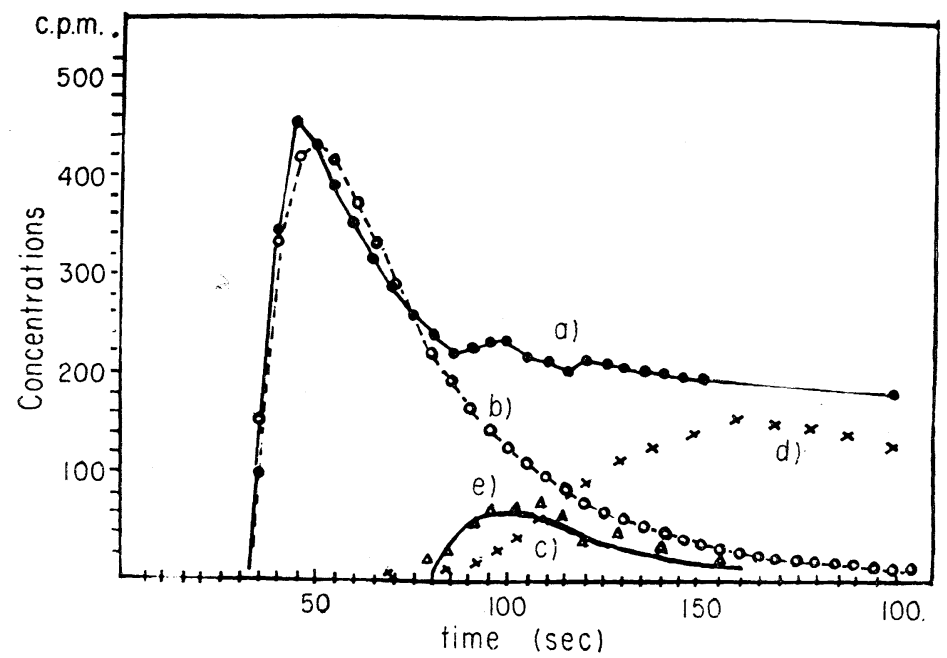

FIG. 4. The calculated (by the new principle) and the observed values. (2 Case 1 Heart Diseases)
a) observed curves
b) $\bigcirc C_{11}(t)$
c) $-C_{12}(t)$
d) $\times C_{2}(t)$
e) $\triangle$ obs. val. $-\left(C_{11}(t)+C(t)\right)$ 




FIG. 5(a). Experiment for obtaining response of the heart pulmonary circulation with exclusion of the recirculation.

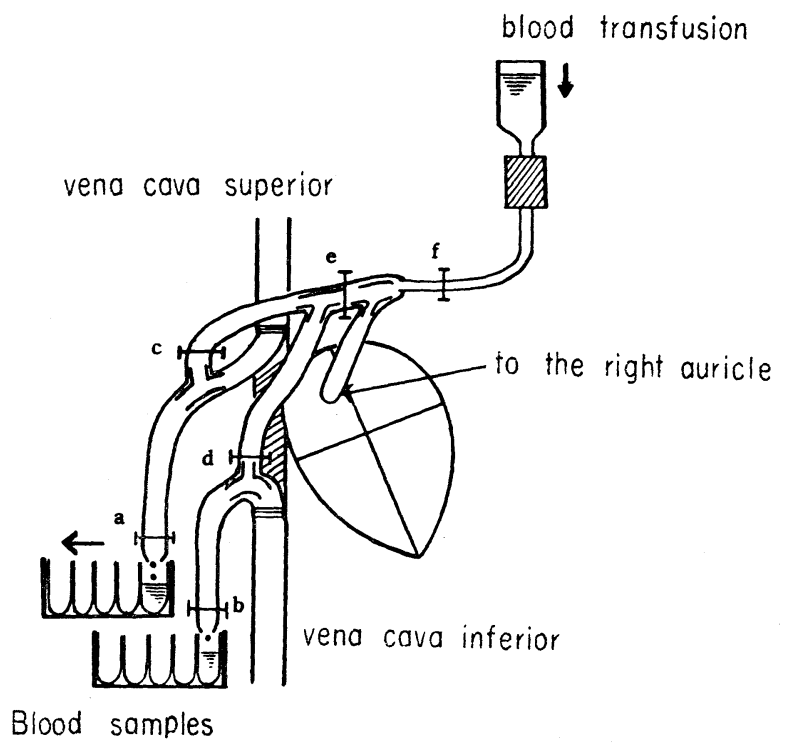

FIG. 5(b). Experiment for obtaining response of the systemic circulation with exclusion of the recirculation. 
with the heart disease, it is not very far from an exponentially descending slope. This tendency was confirmed in many of our own data as well as in the literatures.

\section{EXPERIMENTAL STUDIES}

In the first paragraph the present author proved mathematically on the data reported by other workers that HAMILTON's method of exponential extrapolation could not necessarily be exact in calculating the cardiac out-put. And he proposed a new mathematical method that might replace HAMILTon's Principle.

The following experimental studies were carried out to confirm his mathematical results.

\section{MATERIALS AND METHODS}

Healthy dogs weighing from 13 to $20 \mathrm{kgs}$. were used. The heart-lung preparation and the preparation of the systemic circulation were made as illustrated in the FiG. 5 .

Injected indicators were mostly $T_{1824}$ and Risa. Blood samples were taken serially into the test tubes. The determination of the dyes was done photometrically and that of Risa, with a wet-type scintillation counter.

\section{RESULTS}

1) Response of the heart-lung preparation. When the dye is injected into the right ventricle, the dilution curve did not fall exponentially as the HAMILTON's principle, but there were extra concentration curves which would explain 10$20 \%$ of the whole response. (see FIG. 6). This coincides with the $\theta$ 's obtained in the calculations of the clinical cases. $\theta$ was larger approaching unity, as the cardiac out-put became smaller, while it was less with the increase in the heart stroke volume. This finding had also been expected correctly by the calculations of the recirculation-allowed observations.

The dilution curves of the dye injected into the left ventricle (FIG. 7), descended just exponentially without any notching, although the dye should have entered the bronchial or coronary arteries, which could not be excluded.

2) The response of the preparation of the systemic circulation. After the recirculation through the pulmonary circulatory system was excluded, the dye injected into the left ventricle was diluted when it appeared at the end of the upper and lower cava veins as shown in the FIG. 8. The curve is very much complicated, far from being a single exponential curve.

In FIG. 8, the first peak in the response of superior cava vein seems to indicate the cerebral circulation, while the second peak beginning at 40 seconds 


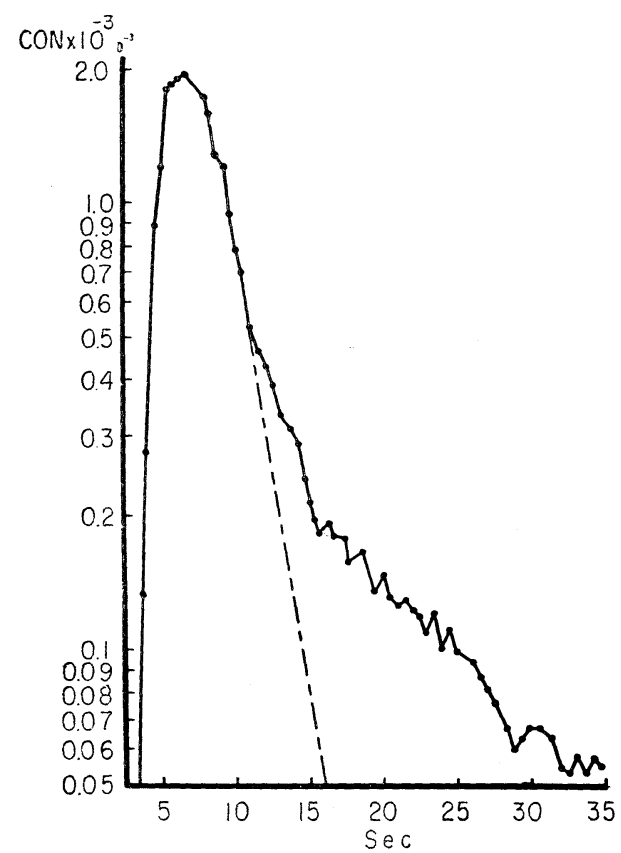

FIG. 6(a). The response of the pulmonary circulation without recirculation $4 \mathrm{ml}$ of $0.5 \%$ Evans blue was injected into the right ventricle. The abscissa indicates the time (in seconds) after the injection. The heart output in each samples was almost constant over the entire observation except rhythmic change from each heart bit. The stroke volume was on average $15.5 \mathrm{ml}$ / seconds. Here $\theta$ was directly calculated with a planiometer as 0.77 .



Fig. 6(b). The same experiment with the same dog. In this case the heart output was set down to $8 \mathrm{ml} /$ second. Here $\theta$ was 0.88 . Note the zigzag curve of the descending slope is very similar to that of FIG. 5 , although $\theta$ is larger in this case. 


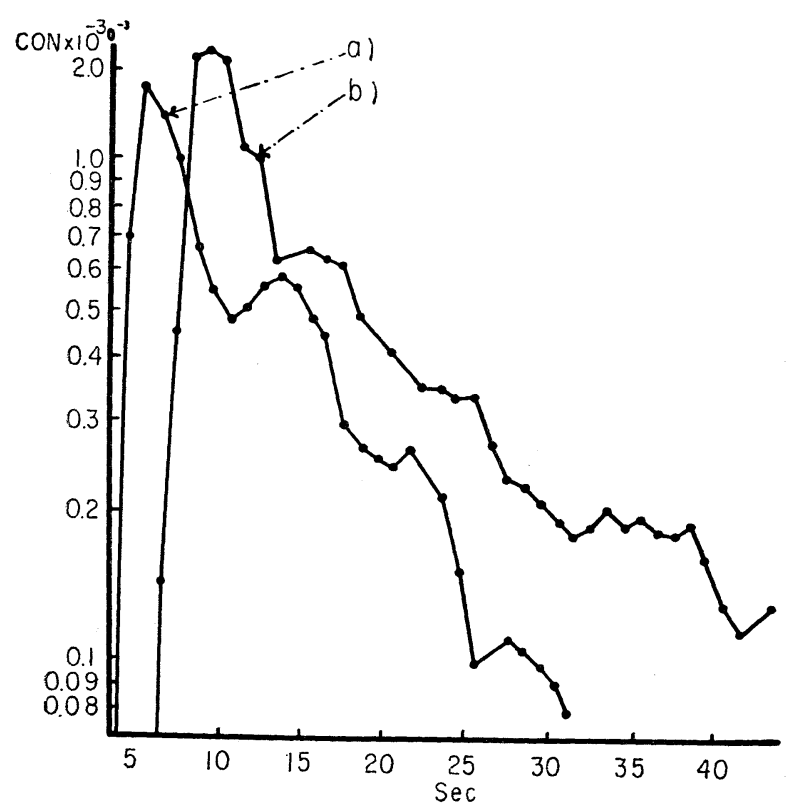

FIG. 6(c). The similar expriment as the FIG. 5 and FIG. 6.

a) The lung kept to be blased. The output: 9.0 $\mathrm{ml} / \mathrm{sec}$.

b) The lung kept to be atorophied. The output was $5.6 \mathrm{ml} / \mathrm{sec}$.

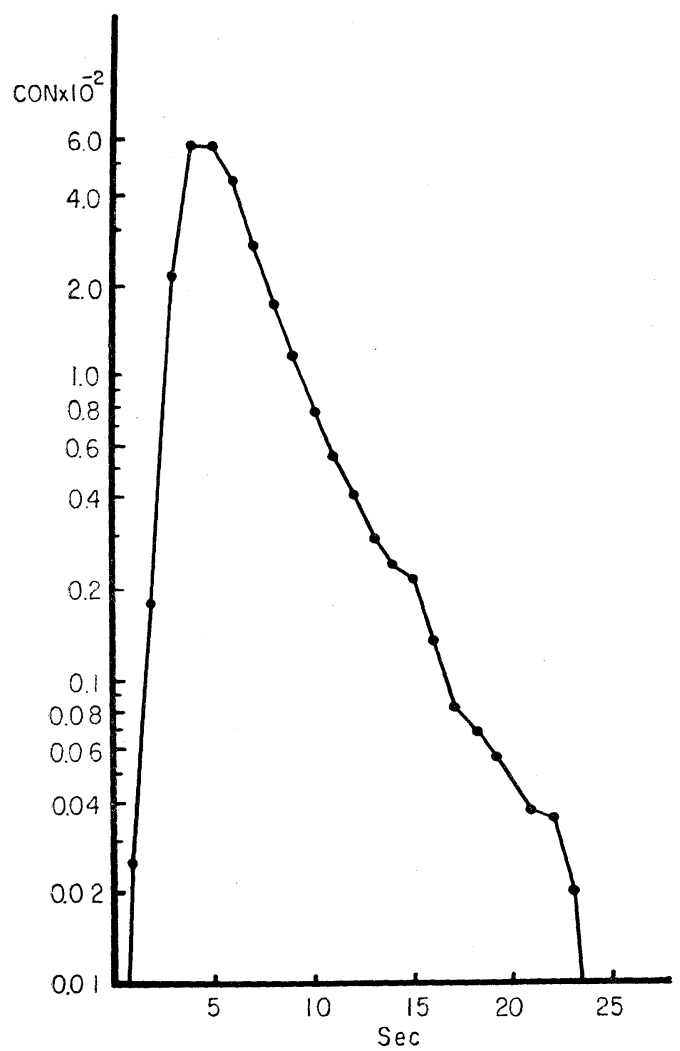

FIG. 7. The response of the left heart: the dye was injected into the left heart in the same experiment as in the above. The heart output was $5.0 \mathrm{ml} / \mathrm{sec}$. 




FIG. 8(a). The response of the systemic circulation without recirculuation: the dye was injected into the left heart ventricle. The concentration was expressed in the mixture of the blood samples of vena cava superior and inferior.

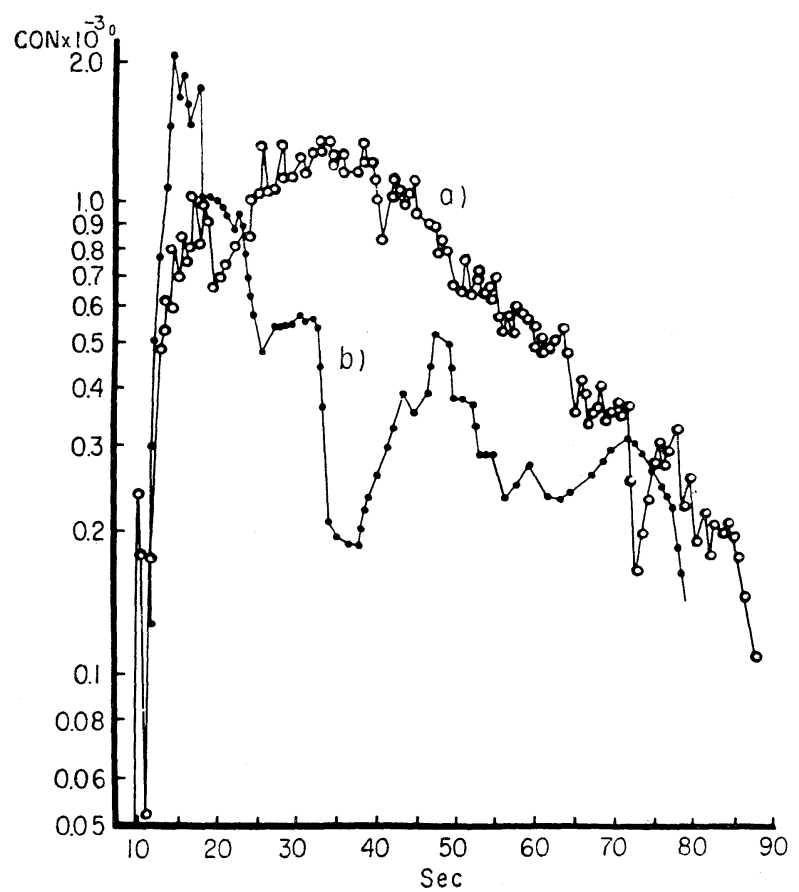

Fig. 8(b). The same experiment: The concentration at vena cava superior and inferior is given separately.

a) vena cava inf.: the output, $7.6 \mathrm{ml} / \mathrm{sec}$.

b) vena cava sup.: the output, $2.5 \mathrm{ml} / \mathrm{sec}$. 


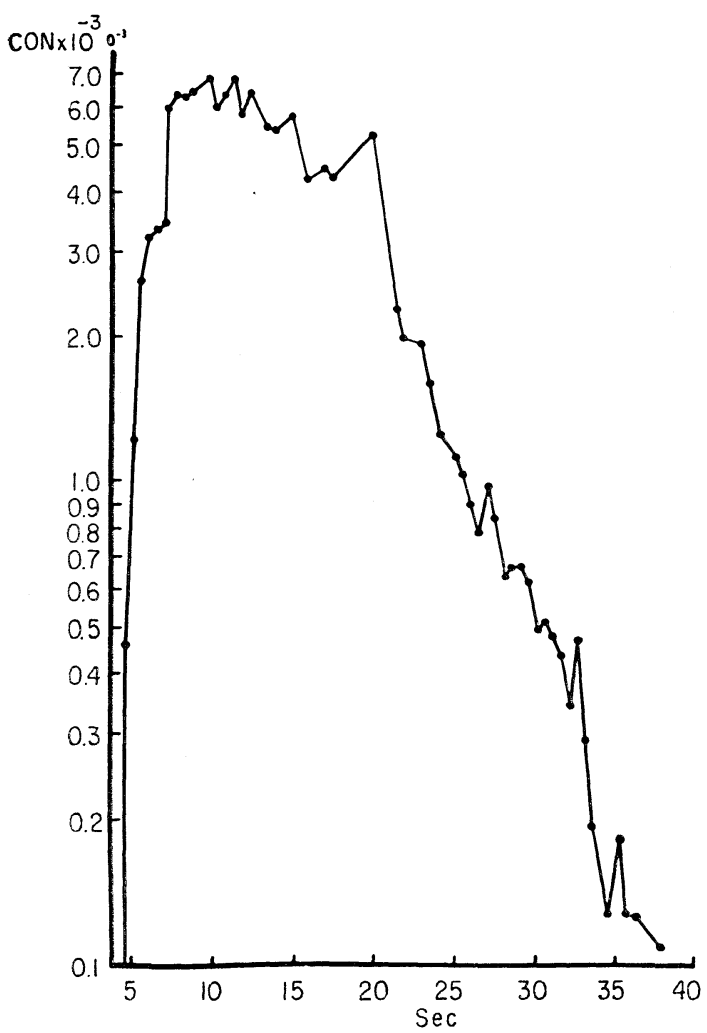

FIG. 9(a). The response of the liver circulation, the recirculation excluded. The dye was injected into the portal vein. Blood was taken from vena cava inferior, where the output was $9.0 \mathrm{ml} / \mathrm{sec}$.

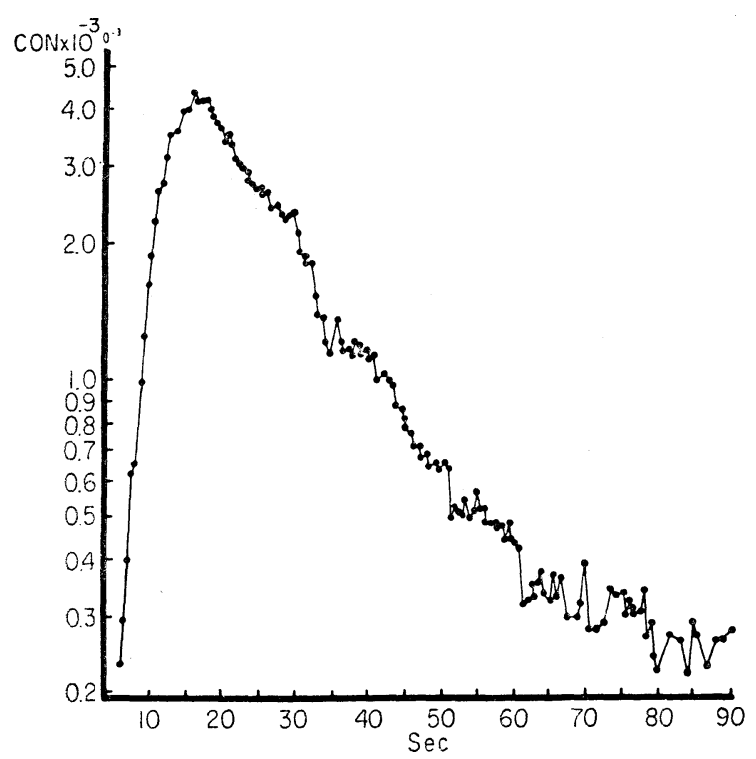

FIG. 9(b). The response of the liver circulation, with exclusion of the recirculation. The dye was injected into the aorta just over the diaphragm, after stoppage of blood flow for 15 seconds into the renal arteries beyond the bifurcation. The hepatic artery was kept to be open. Blood samples were taken at vena cava inferior, whose output was $16.2 \mathrm{ml} /$ sec. 


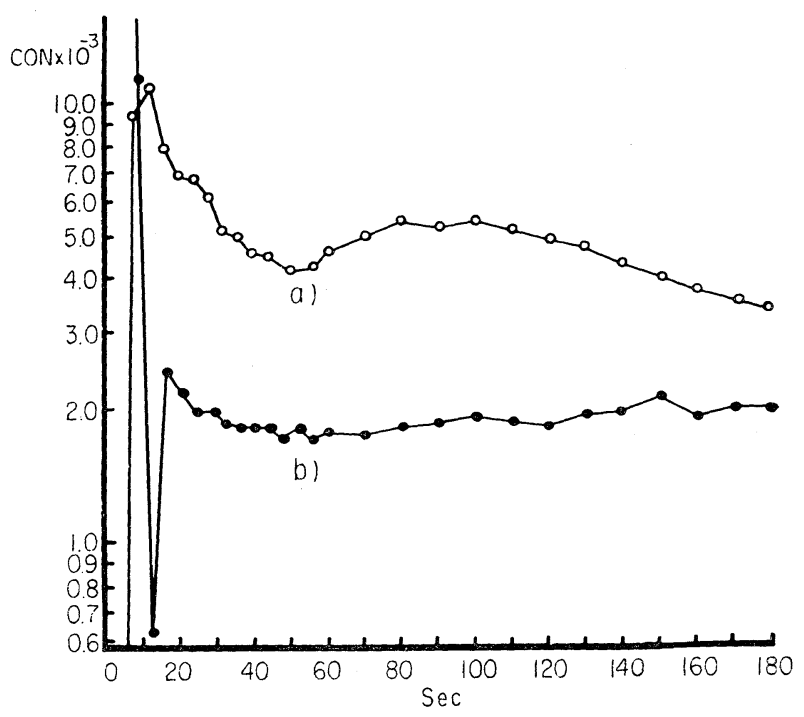

Fig. 10. Response of vena and arteria femoralis, recirculation being allowed: Evans blue was injected into the right femoral artery and concentration of blood samples at the right femoral vein and left femoral artery was measured. A part of the dye was flown directly into the right femoral artery beyond the bifurcation.
a) $\bigcirc$ Vena femoralis
b)
Arteria femoralis

could have been the response of the upper legs and other muscular system. Of the response of the inferior cava vein the earliest part may be that of the dye running through the arterio-venous shunt, and the plateau which continued from 20 to 60 seconds is likely to be the response of the portal vein and the liver circulation. The dilution effect for which the lower legs and other smaller organs are responsible seems to have appeared, being scattered between them. 3) The response of the liver circulation. In FIG. 9 is shown the dilution curve in the inferior cava vein after the dye was injected into the arteries which are supposed to run into the liver, spleen and other digestive system. This pattern is of trapezoid shape with plateau and no separate fast running portion was seen.

4) The response of the leg circulation. When the dye was injected into the femoral artery, the response at the femoral vein of the same side was measured in a nonoperated animal as shown in the FIG. 10. The curves are composed of two components, and do not follow the exponentiality.

5) The response of the cerebral circulation. When the dye was injected into the carotid artery, its concentration in the jugular vein of the same side disclosed a simple exponential curve with relatively small time constant. (FIG. 11) 




FIG. 11. Response of the central circulation, recirculation being allowed. Risa was injected into the left carotid artery.
a) $\bigcirc$ left vena jugularis
b)
right carotid artery

\section{DISCUSSION}

It has been pointed out by some workers ${ }^{8,9)}$ that a primary response of the injected indicators through the heart-lung preparation describes a curve some while away from an exponential in its descending slope. To explain this nonexponential type of response, YUDILEVICH ${ }^{8)}$ considered that this very difference should have been caused by the coronary recirculation. However there is no quantitative proof for that. It was recently reported by C. W. SHEPPARD et $\mathrm{al}^{9)}$ that the non-exponential tail of the dilution curve in the heart-lung preparation could not explain the coronary flow. Besides, the strictly exponential down slope, when the dye was injected into the left heart seemed to indicate that there is no significant dilution curve of the coronary recirculation appearing in the period of the observation.

An exponential washout was observed in perfusion of lungs led through a mixing chamber ${ }^{1}$. This could reflect a certain condition of the living body. C. W. SHEPPARD and others ${ }^{10)}$ proposed different methods of curve fitting to the observed data of the heart-lung preparation. And $\Gamma$ function or $\log$ normal could be another empirical formula of choice.

But we stuck to exponentials, partly because the start-point of the calcula- 
tion originated in HAMILTON-STEWART's principle, and partly because it would be physiologically more reasonable according to NEWMAN's ${ }^{5)}$ concept of chamber models.

The assumption of a single exponential pattern of response through the systemic circulation was proved to be 'robust' for the purpose of estimation of the recirculation curves.

The informations which will be added by the modified formula $\left(C_{11}(t)+C_{12}(t)\right)$ are as follows.

(1) The calculation of the cardiac out-put by our method is important especially from the pathologic-physiological view-point, for the above defined $\theta$ becomes less when the subjects are healthy, but it approaches unity when they are suffering from congestive heart failure.

The comparison of Fick's method and dilution method resulted in a fair coincidence within a range of $25 \%^{11,12,13,14,15,16,17)}$. But the direct measurement of flow with a rotameter ${ }^{18,19)}$ seems to indicate that the dilution method might have overestimated the cardiac out-put with a mean deviation of ca. $10 \%$, considering the coronary flow to be $10 \%$. Most part of these deviations could be explained by the non-exponential pattern of the primary down slope.

(2) The estimation of the pool volume or congestion indices:

$$
L=v \cdot\left\{\theta\left(2 T_{1}+T_{2}+t_{L}\right)+(1-\theta)\left(2 T_{2}+T_{4}+t_{j}\right)\right\}
$$

Congestion indices $=\theta\left(2 T_{1}+T_{2}+t_{L}\right)+(1-\theta)\left(2 T_{5}+T_{4}+t_{j}\right)$

The same formula could be obtained by the calculation of the product $v \times$ mean transit time. The latter has been usual in the previous literatures. ${ }^{20}$

(3) The pattern of the dilution curve. As it was mentioned above, the pattern of the curve may indicate some dynamic state of circulation through the heart and lungs, though we could not go into the detail on that point.

These relations will be interesting, when we consider about the pharmacological aspect of the heart disease. For instance, when Aminophyline is injected to a patient of heart disease, the dilution curve shifts biphasic from monophasic in addition to the increase in the heart out-put and decrease in the pool volume. Heretofore all the changes were attributed to the increase in the heart-output, but according to the new formulae the out-put is not so much increased as they considered but there is a change in the pattern of the dilution curve, which may also be important.

\section{CONCLUSION AND SUMMARY}

The present author led a theoretical formula of the dilution curve of intravenously injected substances with full consideration of its recirculation. By this new mathematical procedure, a primary response of the injected substances through the pulmonary circulatory system was obtained from the clinical data 
in which the recirculation of the substance could not be avoided.

As a result it was concluded that the HAMILTON-STEWART's principle of exponentially descending slope would overestimate, cardiac out-put in some cases. The author's mathematical analysis could correct this deviation whenever it exists.

The favorable experimental findings for the criticism of his were discussed from the findings reported in the literatures as well as our own experimental data. This new principle of dilution curves might lead to a different interpretation on the hemodynamics of pathologic conditions.

The author would like to suggest that some works in the foregoing literatures on the hemodynamics by the HAMILTON-STEWART's principle should be reconsidered with this new modified principle.

\section{REFERENCES}

1) Howard, A. R., W. F. Hamilton and P. Dow, Am. J. Physiol. 175: 173, 1953.

2) Churchill, Ruel V. Modern operation mathematics in engineering. New York and London: Macgrow-Hill Book Company, Inc.

3) Stephenson, J. L. Bull. of Mathem. Biophysics. 10: 117 (1948).

4) Kinsman, J. M., J. W. Moor and W. F. Hamilton. Am. J. Physiol. 89 : 322 (1929).

5) Newman, E. V., M. Merrell, A. Genecin, C. Monge, W. R. Milnor and W. P. MCKeener. Circulation. 4 : 735 (1951).

6) Nylin, G. and H. Celander. Circulation. 1: 76 (1950).

7) Deming, W. E. Statistical adjustment of data. N. Y. John Wiley \& Sons (1943).

8) Yudilevich, D. Circulation Research. 9: 925 (1961).

9) Crowder II, B. L., W. C. Greer and C. W. Sheppard. The physiologist. $3: 3$ ( 2).

10) Sheppard, C. W., M. P. Jones and E. L. Murphew. Circulation Research. 9: 1, (1961).

11) Hamilton, W. F., G. W. Moore, J. M. Kinsman and R. G. Spurling. Am. J. Physiol. $84: 338$ (1928).

12) Hamilton, W. F., R. L. Riley, A. M. Attyah, A. Cournand, D. M. Fowell, A. Himmelstein, R. P. Noble, J. W. Remington, D. W. Richards, Jr, A. C. Wheeler And A.C. With am. Am. J. Physiol. $153: 309$ (1948).

13) Werkö, L., H. Lagerhof, P. Bucht, B. Wekle and A. Holmgren. Scandinav. J. Clin. \& Lab. Invest. 109: (1949).

14) Kopelman, H. and G. Lee de J. Clin. Sci. 10:383 (1951).

15) Doyle, J.T., J.S. Wilson, C. Le Pine and J. V. Warren. J. Lab. \& Clin. Med. $41: 29$ (1953).

16) Gilmore, H. R.. M. Hamilton, H. Kopelman and L.S. Sommer. Brit. Med. J. $16: 301$ (1954).

17) Falholt, W., and J. Fabricus. Dan. Med. Bull. $3: 55$ (1956).

18) Shaddle, O. W., T. B. Ferguson, D. E. GregG, and S. R. Gilford. Circulation Research. $1: 200$ (1953).

19) Macintyre, W. J., W.H. Prichard, R. W. Eckstein and H. L. Frideell. Circulation. $4: 552$ (1951).

20) Meier, P. And K. L. Zierler. J. Appl. Physiol. $6: 731$ (1954). 